\section{Ultrasonographic evaluation of women with pathologic nipple discharge}

\author{
Jung Hyun Yoon, Haesung Yoon, Eun-Kyung Kim, Hee Jung Moon, Youngjean Vivian Park, \\ Min Jung Kim
}

Department of Radiology and Research Institute of Radiologic Science, Severance Hospital, Yonsei University College of Medicine, Seoul, Korea

Nipple discharge is a common symptom that is alarming for the patient since it can be a presenting symptom of breast cancer. Breast imaging is used to examine women with pathologic nipple discharge in order to detect any lesions that may be present and to assist in the differential diagnosis. The modalities of breast imaging include mammography, breast ultrasonography (US), and magnetic resonance imaging. Breast US is currently considered to be useful for the visualization of ductal structures and intraductal lesions that cause nipple discharge. In this review, we discuss US techniques that assist in the clear visualization of ductal structures and intraductal lesions in patients with nipple discharge. Controversy remains regarding the evaluation and management of patients with nipple discharge, and we summarize the results available in the currently published literature.

Keywords: Breast; Breast diseases; Ultrasonography; Nipple discharge

\section{Introduction}

Nipple discharge accounts for $2 \%-10 \%$ of the symptoms that women report when they seek care at breast clinics [1,2] and is alarming for both patients and clinicians since it is a presenting sign of breast cancer. Nipple discharge can result from various physiologic or pathologic causes, and accurately identifying the causative condition is critical for patient management. Despite the anxiety it causes, most underlying causes of nipple discharge are benign, as the cancer rate in patients with nipple discharge has been reported to be $5 \%-21.3 \%[1,3-5]$. A thorough investigation of the patient is warranted, with a physical examination and breast imaging to accurately distinguish patients who require surgical treatment for breast cancer from those who may be managed conservatively. Herein, we review the causes of nipple discharge, the ultrasonographic (US) imaging techniques used to evaluate the cause of nipple discharge, and the management of patients with nipple discharge.

\section{Pathogenesis of Nipple Discharge}

Nipple discharge is defined as a true, direct drainage from the mammary ducts that grossly appears at the surface of the nipple [2]. Grossly apparent nipple discharge is due to (1) excess secretions due to physiologic or hormonal causes, or (2) obstructive breast masses or lesions located within

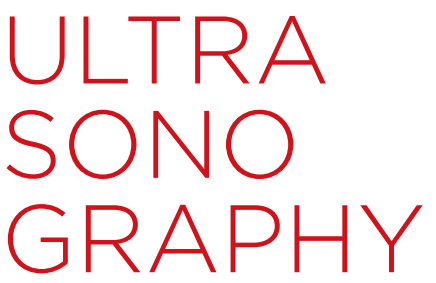

REVIEW ARTICLE

https://doi.org/10.14366/usg. 17013 pISSN: 2288-5919 - elSSN: 2288-5943 Ultrasonography 2017;36:310-320

Received: February 13, 2017

Revised: April 3, 2017

Accepted: April 9, 2017

Correspondence to: Min Jung Kim, MD, PhD, Department of Radiology and Research Institute of Radiological Science, Severance Hospital, Yonsei University College of Medicine, 50-1 Yonsei-ro, Seodaemungu, Seoul 03722, Korea

Tel. $+82-2-2228-7400$

Fax. $+82-2-393-3035$

E-mail: mines@yuhs.ac

This is an Open Access article distributed under the terms of the Creative Commons Attribution NonCommercial License (http://creativecommons.org/ licenses/by-nc/3.0/) which permits unrestricted noncommercial use, distribution, and reproduction in any medium, provided the original work is properly cited.

Copyright $\odot 2017$ Korean Society of Ultrasound in Medicine (KSUM)

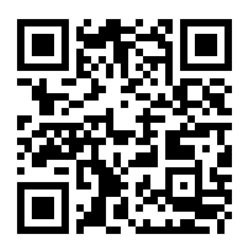

How to cite this article:

Yoon JH, Yoon H, Kim EK, Moon HJ, Park YV, Kim MJ. Ultrasonographic evaluation of women with pathologic nipple discharge. Ultrasonography. 2017 Oct;36(4):310-320. 
the ductal structures that either block the ductal drainage system or independently cause excess secretions within the duct (Fig. 1). Based on its origin, nipple discharge can be categorized as physiologic or pathologic discharge. Physiologic nipple discharge includes galactorrhea following normal hormonal stimulation during pregnancy or lactation. This condition can persist for more than 1 year after discontinuing breast feeding. Other than pregnancy or lactation, elevated levels of prolactin or thyroid-stimulating hormone can induce galactorrhea, and the clinician should determine whether underlying conditions causing these hormonal abnormalities are present.

Pathologic nipple discharge is defined as spontaneous, unilateral, bloody, or serous discharge, often arising from a single duct [1]. Common causes for pathologic nipple discharge are intraductal papilloma, duct ectasia, inflammation, and breast cancer, among which intraductal papilloma is most common, accounting for approximately $57 \%$ of cases [1]. Table 1 summarizes the characteristics of physiologic and pathologic nipple discharge.

\section{Evaluation of Patients with Nipple Discharge}

With the exception of physiologic galactorrhea seen in pregnant or lactating women, a thorough investigation of the cause of nipple discharge must be performed. A detailed history including the patient's medical history and a physical examination evaluating the characteristics of the nipple discharge should be carried out as the first step; this is important, because these steps provide information useful for characterizing the nipple discharge and deciding upon the next step in patient management. A physical examination is needed to locate breast masses associated with the nipple discharge. If

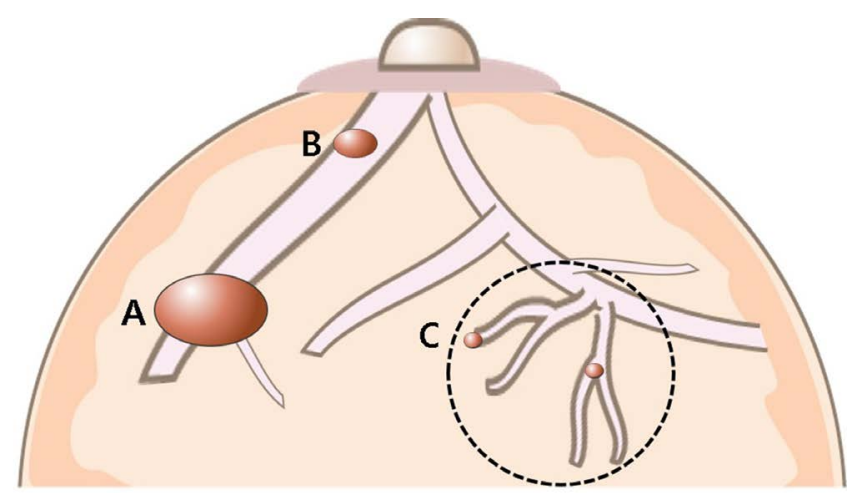

Fig. 1. Pathogenesis of pathologic nipple discharge. Other than physiologic causes, obstructive lesions in the breast that either block the ductal drainage system $(A)$ or independently form excess secretions within the central (B) or peripheral ductal system (C, dotted circle) are common causes of nipple discharge. the discharge is considered to be physiologic based on the clinical information and characteristics of the nipple discharge, no further imaging studies of the breast are warranted if the patient is under the age of 40 years or over 40 years with up-to-date routine screening mammography. If the discharge is considered to be pathologic, all women should have breast imaging examinations, regardless of age (Fig. 2).

\section{Imaging Workup}

Approximately $80 \%-90 \%$ of patients with pathologic nipple discharge have been reported to have benign conditions [1,3-6], but since the risk of breast cancer cannot be completely excluded, surgical duct excision is commonly considered. Breast imaging is used to evaluate women with pathologic nipple discharge for two common purposes: first, to localize the lesion that can explain the origin of the pathologic nipple discharge, and second, to determine whether the pathologic nipple discharge is caused by a cancerous lesion. Several reports have proven that mammography and breast US are useful for detecting the pathologic causes of nipple discharge $[3,7]$, and especially for detecting findings indicative of breast cancer. Still, controversy remains regarding whether breast imaging helps in triaging patients who need immediate surgical intervention from those who can be managed conservatively, but in general the role of breast imaging is being increasingly emphasized for the following reasons. First, breast imaging enables the localization of the breast abnormalities causing the pathologic nipple discharge, which helps to minimize the number of operations and/or the extent of surgery. Second, localizing the origin of pathologic nipple discharge enables percutaneous biopsy under imaging guidance,

Table 1. Comparison of the characteristics of physiologic and pathologic nipple discharge

\begin{tabular}{lll}
\hline Characteristic & \multicolumn{1}{c}{$\begin{array}{c}\text { Physiologic nipple } \\
\text { discharge }\end{array}$} & \multicolumn{1}{c}{$\begin{array}{c}\text { Pathologic nipple } \\
\text { discharge }\end{array}$} \\
\hline Manifestation & $\begin{array}{l}\text { Bilateral } \\
\text { Multiple ducts } \\
\text { Resolves spontaneously } \\
\text { Clear or white, yellow, } \\
\text { green, brown, gray }\end{array}$ & $\begin{array}{l}\text { Unilateral } \\
\text { Single duct } \\
\text { Intermittent, persistent }\end{array}$ \\
Blood tests & $\begin{array}{l}\text { Begative, regardless of } \\
\text { color }\end{array}$ & Positive \\
Causes & $\begin{array}{l}\text { Pregnancy/lactation } \\
\text { Nipple stimulation/breast } \\
\text { compression }\end{array}$ & Duct ectasia \\
& Endocrine abnormalities & Mastitis \\
& Medications & Breast cancer \\
\hline
\end{tabular}




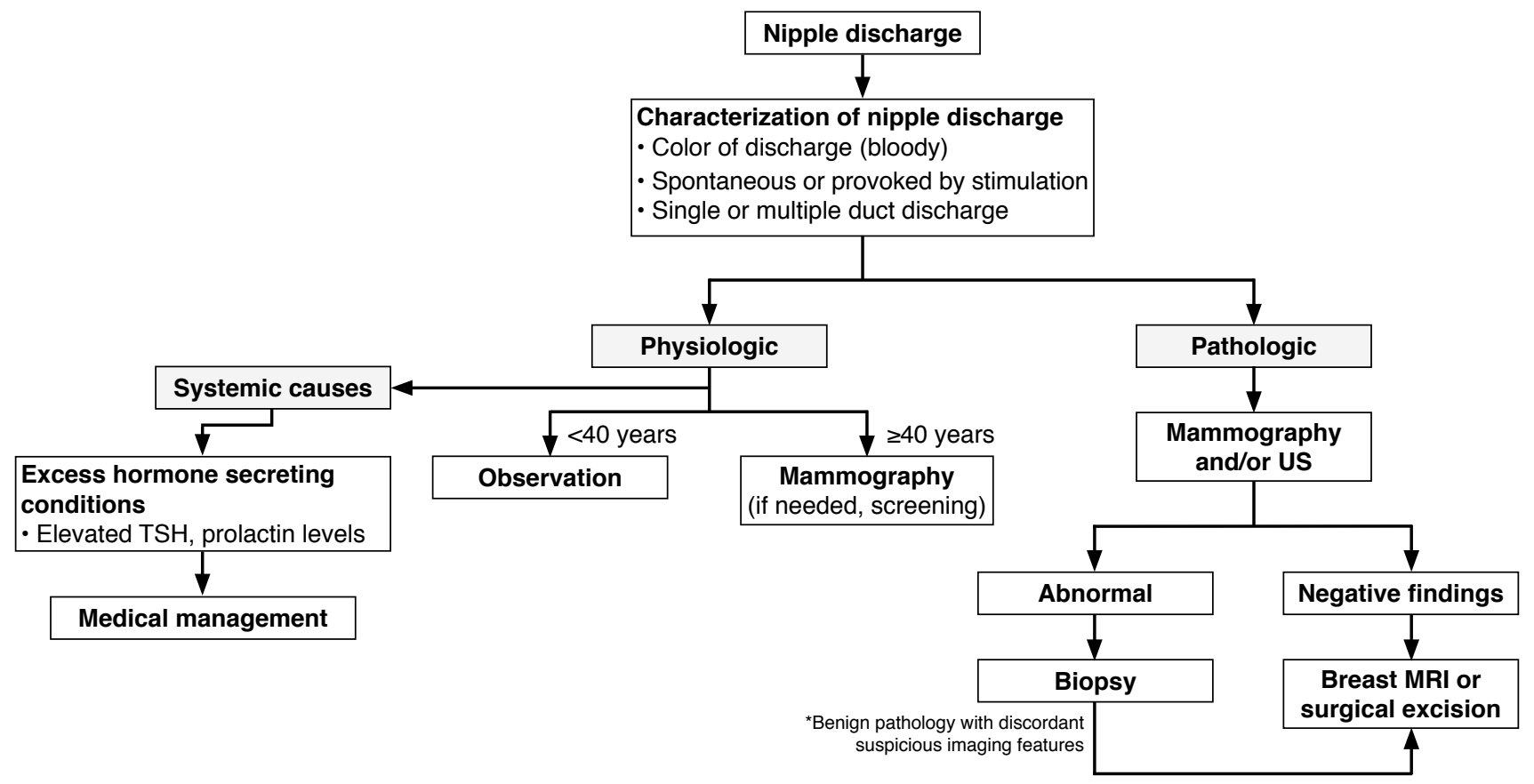

Fig. 2. Workflow for the evaluation of women with nipple discharge. TSH, thyroid-stimulating hormone; US, ultrasonography; MRI, magnetic resonance imaging.

which allows clinicians to be more confident when deciding upon management, and in particular when choosing whether to perform minimally invasive percutaneous vacuum-assisted excision in these patients.

Imaging Modalities Used for Women with Nipple Discharge The imaging findings associated with pathologic nipple discharge may vary according to its origin and the imaging modality applied. Among the common imaging modalities currently available for breast imaging, mammography is commonly recommended for women presenting with nipple discharge. Mammography can reveal masses, microcalcifications, and architectural distortions that may be associated with the underlying pathologic cause of nipple discharge. However, the sensitivity of mammography in detecting the lesion causing the pathologic nipple discharge is very low $[6,7]$, since intraductal masses or masses in the subareolar region tend to be small and lack microcalcifications, in addition to the fact that the subareolar region normally shows increased density that can easily [7]. Ductography and galactography have been used in the past to visualize the number, location, and extent of the involved milk ducts in women with pathologic nipple discharge $[5,8,9]$, but ductography is an invasive imaging method that requires iodinated contrast media injection, and also has low diagnostic accuracy since the differential diagnosis of the causative lesion cannot be completed based on ductographic findings alone $[10,11]$. Several studies have proposed applying breast magnetic resonance imaging (MRI) to evaluate patients who have pathologic nipple discharge, especially in patients who have negative findings on mammography or US $[7,12-14]$, but the usefulness of MRI is limited by the fact that it is very expensive, not readily available in all areas, and requires contrast media injection.

\section{Breast US in Women with Nipple Discharge}

Breast US is used as an adjunct to mammography for breast imaging, enabling the further characterization of abnormalities detected on mammography and providing biopsy guidance. With recent improvements in technology, US is particularly useful in women with pathologic nipple discharge, since it enables the visualization of ductal pathologies that are smaller than a centimeter, as well as associated ductal changes that cannot be detected on mammography, especially in women with dense breasts $[1,5,9,13]$. For women with pathologic nipple discharge, US enables detection of the causative lesion(s), along with orientation of the surrounding ductal structures involved, which is helpful in planning the method of biopsy or the extent of surgery. Although mammography is recommended for women over 40 years old who exhibit pathologic nipple discharge, a recent study showed that adding US to diagnostic mammography can help detect additional 
cancers in women with pathologic nipple discharge [4]. Also, the addition of US in patients with pathologic nipple discharge who had negative findings on mammography led to the detection of malignancies in $15.1 \%$ of these patients by US-guided core needle biopsy, without additional diagnostic surgery [15]. Applying subareolar US in patients with pathologic nipple discharge has also eliminated ductography from diagnostic evaluations $[6,16]$, since US is a less invasive imaging method that is more comfortable for the patient and involves no radiation exposure, while showing similar diagnostic performance to ductography [7]. The findings in the literature regarding the diagnostic performance of mammography, US, and breast MRI in patients with pathologic nipple discharge are summarized in Table 2.

\section{Interpretation of Causative Lesions Detected on Breast US}

In patients with grossly apparent pathologic nipple discharge, localizing the breast mass causing the nipple discharge and evaluating the ductal structures involved with, surrounding, or connected to the causative mass is important for planning the extent of surgery or the further management of the patient. According to the American College of Radiology Breast Imaging Reporting and Data System (ACR BI-RADS) [17], various US features are used for describing and differentiating benign and malignant breast lesions. The ACR BI-RADS categorizes duct changes as "associated features," and abnormal duct changes are defined as (1) cystic dilatation of duct/ducts containing irregular calibers or branching; (2) extension

Table 2. Diagnostic performance of mammography, US, and MRI in the diagnosis of breast cancer among women with pathologic nipple discharge

\begin{tabular}{|c|c|c|c|c|c|c|c|c|c|c|c|c|}
\hline \multirow{2}{*}{ Study } & \multicolumn{4}{|c|}{ Mammography } & \multicolumn{4}{|c|}{ US } & \multicolumn{4}{|c|}{ MRI } \\
\hline & SEN & SPE & PPV & NPV & SEN & SPE & PPV & NPV & SEN & SPE & PPV & NPV \\
\hline Yoon et al. [4], 2015 & 67.9 & 90.3 & 65.5 & 91.2 & 82.4 & 55.5 & 27.7 & 93.8 & - & - & - & - \\
\hline Cabioglu et al. [5], 2003 & 68.4 & 75.7 & 41.9 & 90.3 & 80 & 61.2 & 37.8 & 90.9 & - & - & - & - \\
\hline Ashfaq et al. [6], 2014 & 22 & 94 & 15 & - & 100 & 73 & 17 & - & 50 & 57 & 25 & - \\
\hline Bahl et al. [7], 2015 & 56 & 75 & 29 & 90 & 15 & 98 & 58 & 86 & - & - & - & - \\
\hline Adepoju et al. [13], 2005 & 10 & 94 & 18 & 88 & 36 & 68 & 14 & 89 & - & - & - & - \\
\hline Dolan et al. [20], 2010 & 60 & 99.4 & - & - & 65 & 99.6 & - & - & - & - & - & - \\
\hline Blum et al. [8], 2015 & - & - & - & - & 43 & 31 & 8 & 79 & - & - & - & - \\
\hline
\end{tabular}

Values are presented as percentage.

US, ultrasonography; MRI, magnetic resonance imaging; SEN, sensitivity; SPE, specificity; PPV, positive predictive value; NPV, negative predictive value.

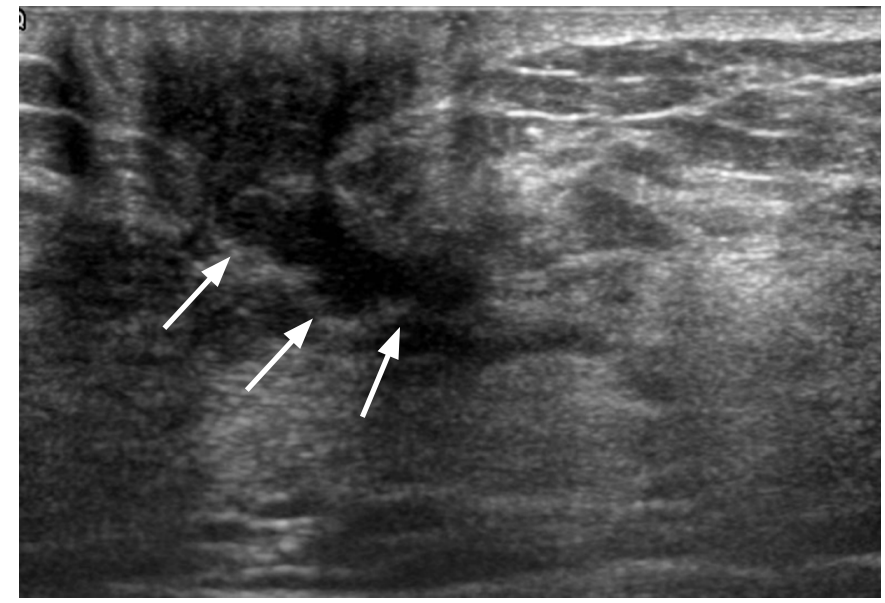

A

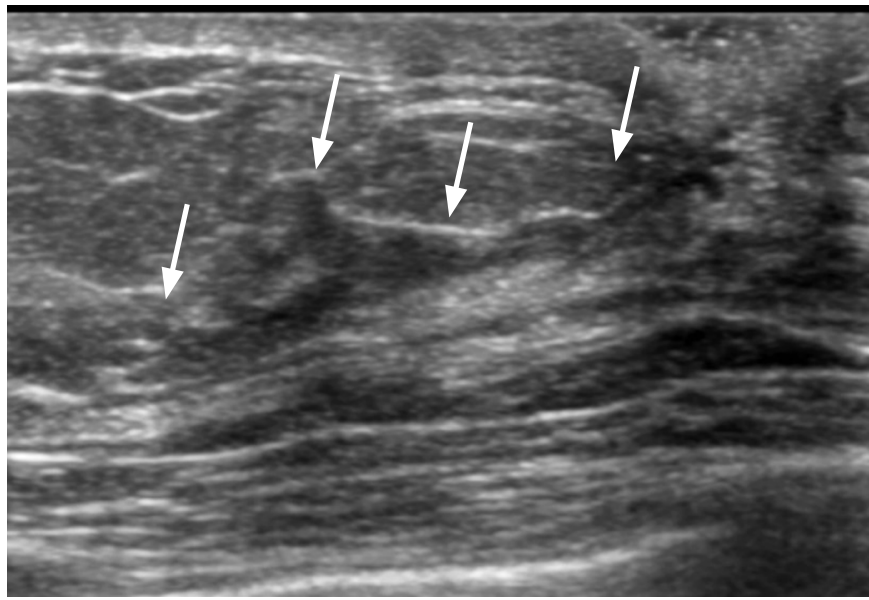

B

Fig. 3. Ultrasonography of abnormal duct changes defined in the "associated features" of the ACR BI-RADS lexicon for breast ultrasonography.

Abnormal duct changes are defined as (1) cystic dilatation of duct/ducts ( $A$, arrows) containing irregular calibers or branching ( $B$, arrows), 


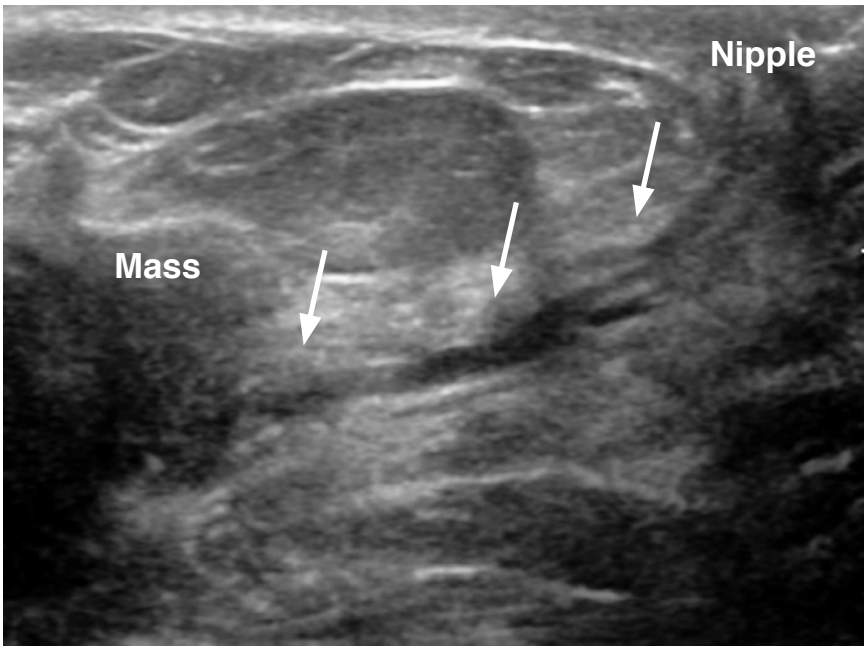

C

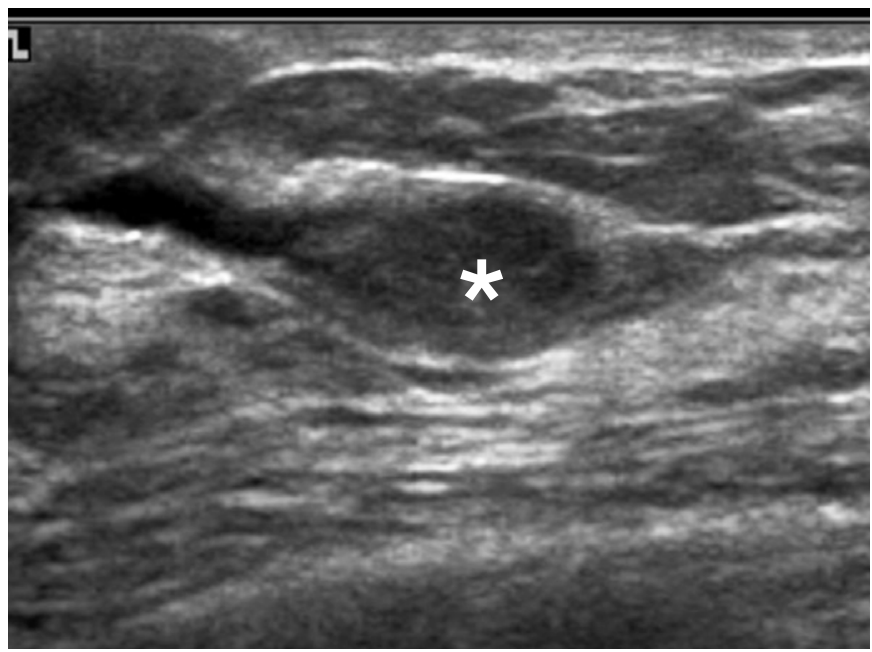

D

Fig. 3. (2) extension of dilated ducts from a malignant mass (C, arrows), or (3) the presence of an intraductal mass, thrombus, or debris ( $D$, asterisk). ACR BI-RADS, American College of Radiology Breast Imaging Reporting and Data System.

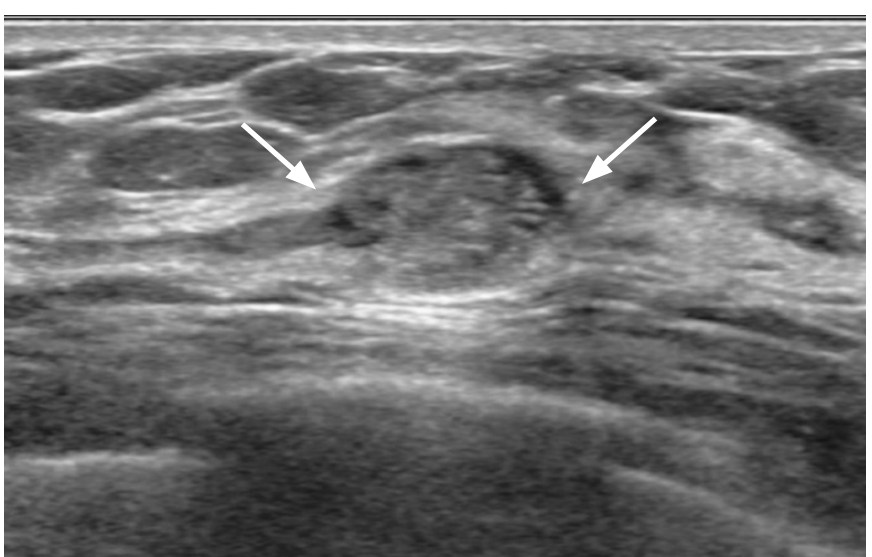

A

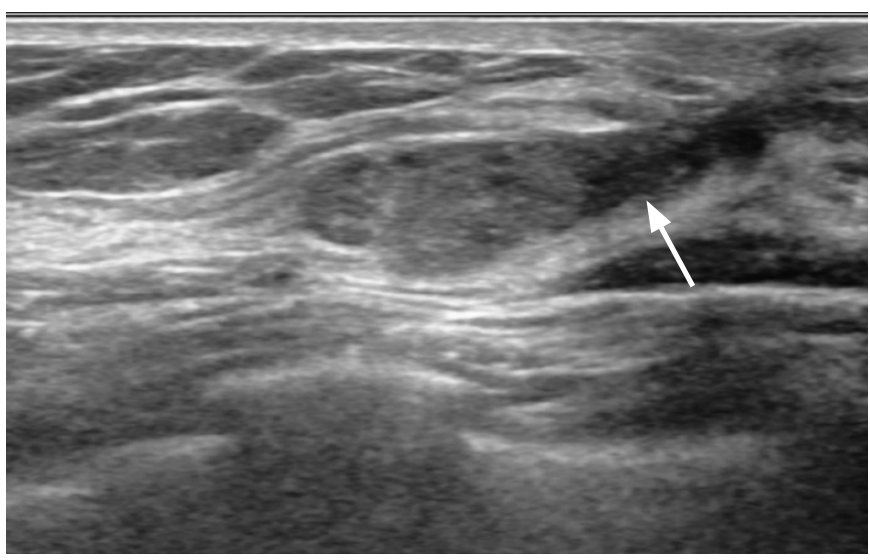

C

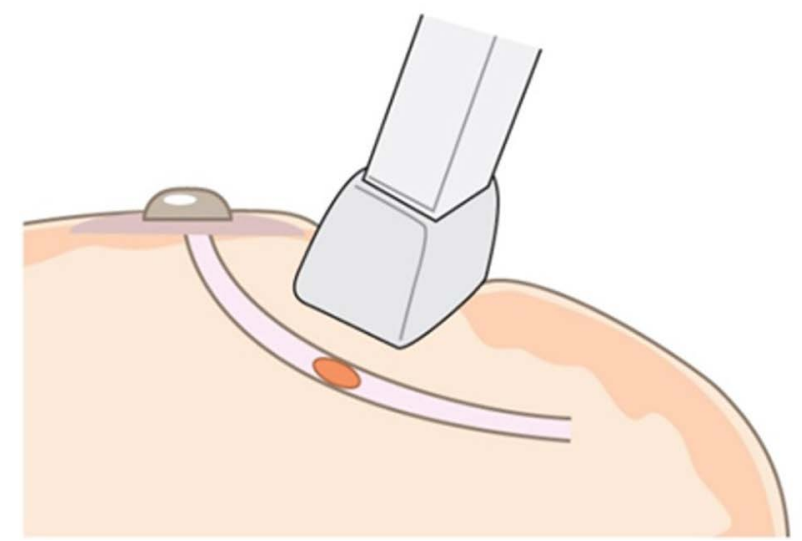

B

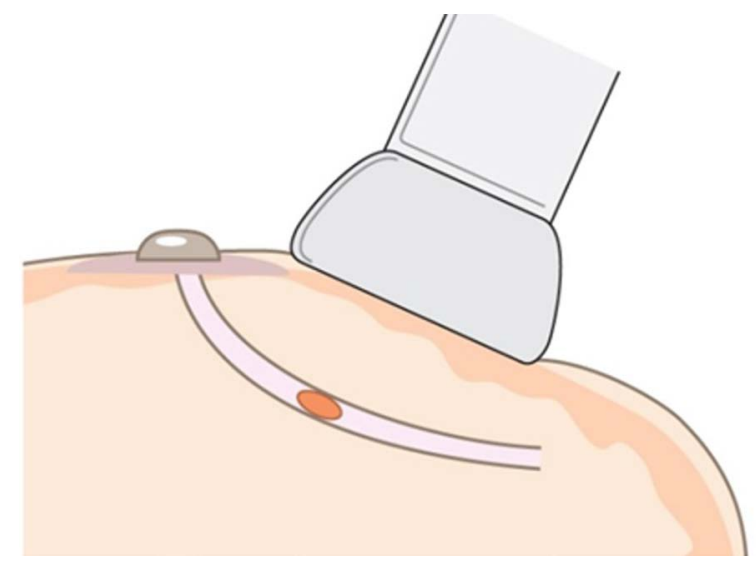

D

Fig. 4. Applying different angles during ultrasonography scanning for ductal orientation.

If an intraductal lesion (arrows) is suspected on either transverse or longitudinal scans (A, B), radial scans obtained by positioning the ultrasonography probe parallel to the longitudinal plane of the intraductal lesion (D) show the extent of the involved duct and the connection towards the nipple ( $C$, arrow). 
of dilated ducts from a malignant mass; or (3) the presence of an intraductal mass, thrombus, or debris (Fig. 3) [17]. Among the duct changes, intraductal masses are at present recommended to be assessed as category $4 a$, indicating a need for biopsy because these intraductal masses have an $8 \%$ risk of malignancy [17-19]. Still, it is not clear whether all intraductal masses should be biopsied, and considerable overlap is seen between benign and malignant intraductal masses, as demonstrated in a recent study [18]; although none of the intraductal masses that only partially filled the duct were proven to be cancers, approximately $92 \%$ of the intraductal masses that completely filled the duct were likewise shown to be benign. In addition, in cases when irregular masses show intraductal extension, a precise description of the extent of the surrounding ductal structures in addition to the irregular mass is required, because these ductal extensions often represent ductal carcinoma in situ components surrounding an invasive carcinoma. For intraductal masses, a description of the length of the duct segment containing the mass or debris, the size of the intraductal mass, and the distance from the nipple are important factors that are required in US reports.

\section{Tips on Identifying Causes of Nipple Discharge Using Breast US}

In patients with pathologic nipple discharge, US is capable of visualizing ductal structures located in the subareolar region that can be easily obscured on mammography in patients with dense breasts. One drawback of breast US is that it is operator-dependent, and visualization of the subareolar portion of the breast can be difficult, requiring experience in breast imaging. Ductal diseases are a major challenge in terms of diagnostic imaging, since visualizing ductal structures is particularly difficult, especially if the pathologic entity involves small distal ducts, and does not produce sufficient

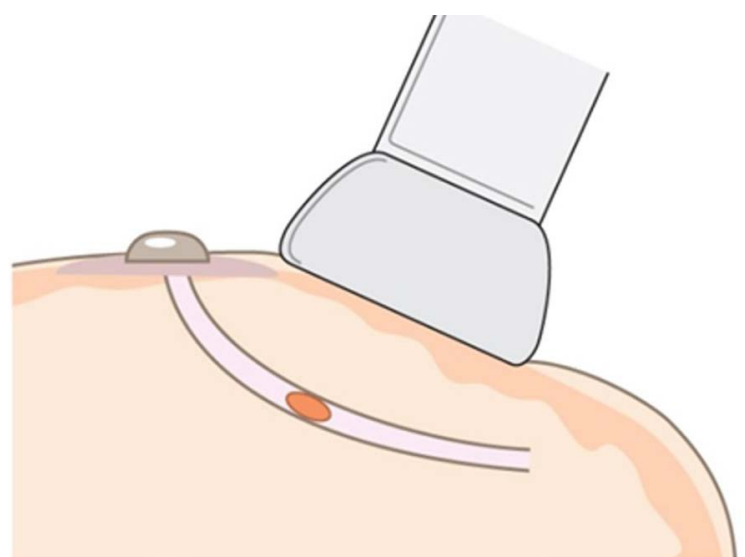

A

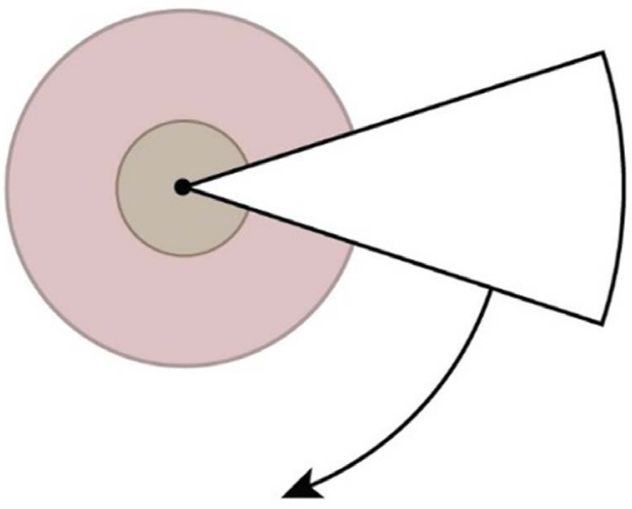

C

Fig. 5. Radial scans for evaluating the extent of the ductal structures involved.

With the probe in the radial plane (A), the intraductal mass causing the nipple discharge is located, along with the dilated ducts extending towards the nipple (B, arrow). By rotating the probe in a clockwise/counterclockwise direction (C), the associated minor ductal structures can be visualized ( $D$, arrows) along with the full extent of the diseased duct ( $D$, dotted circle).

e-ultrasonography.org

Ultrasonography 36(4), October 2017 
material to dilate the ducts. Adding to this, the acoustic shadowing that is commonly seen beneath the nipple-areolar complex due to the gathering of the major ducts, the uneven skin surfaces of nippleareolar complex, or the protuberance of the nipple itself interferes with clear visualization of the ductal structures.

\section{Radial Scans}

Applying the US probe at different angles helps to accurately detect the intraductal mass and/or to delineate the ductal structure involved. When an intraductal lesion is suspected, radial scans are helpful in visualizing the extent and direction of the duct involved, by positioning the US probe parallel to the long axis of the detected intraductal lesion (Fig. 4). Additionally, radial scans are helpful in detecting the ductal structures involved near the intraductal lesion causing the pathologic discharge, as well as lesions located in the peripheral ducts (Fig. 5).

\section{Peripheral Compression Technique}

The nipple or areolar tissues may hinder the detection of lesions due to acoustic shadowing, so techniques for maneuvering the nipple area to reduce the shadowing helps in visualizing subareolar ductal structures. The transducer is positioned radially, parallel to the long axis of the diseased duct. Compression is then applied to the lateral end of the transducer, flattening out the nipple-areolar area and

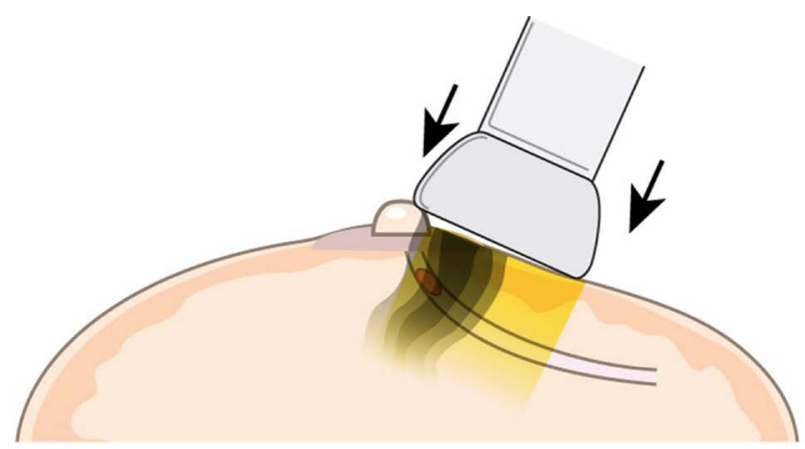

A

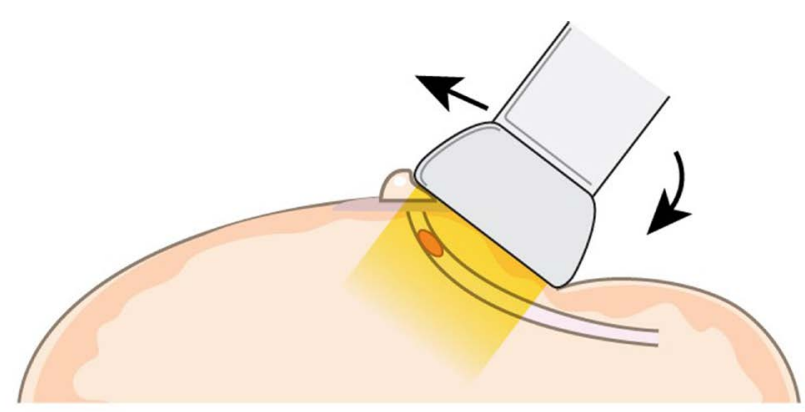

bending the nipple to the other side (Fig. 6).

\section{Rolled-Nipple Technique}

While the peripheral compression technique involved bending the nipple with the transducer, the rolled-nipple technique requires manual compression by the performer. As the targeted duct is localized with the transducer positioned parallel to its long axis, the index finger of the free hand of the performer is positioned at the nipple, opposite from the transducer. By sliding the transducer towards the nipple, the nipple is gradually rolled over the index finger, producing firm adherence of the probe to the skin and flattening out the area that needs visualization (Fig. 7). When using this technique, performers must be cautious to apply light compression with the transducer to avoid collapsing the dilated ductal structures.

\section{Two-Handed Compression Technique}

Intraductal lesions often produce secretions that fill up the ducts, causing duct dilatation and nipple discharge. On breast US, these secretions appear as echogenic material within the ducts, mimicking intraductal solid masses. The two-handed compression technique is useful in differentiating intraductal debris from true masses, as the external compression can collapse ducts containing only secretory material, but not ducts containing masses. With the transducer

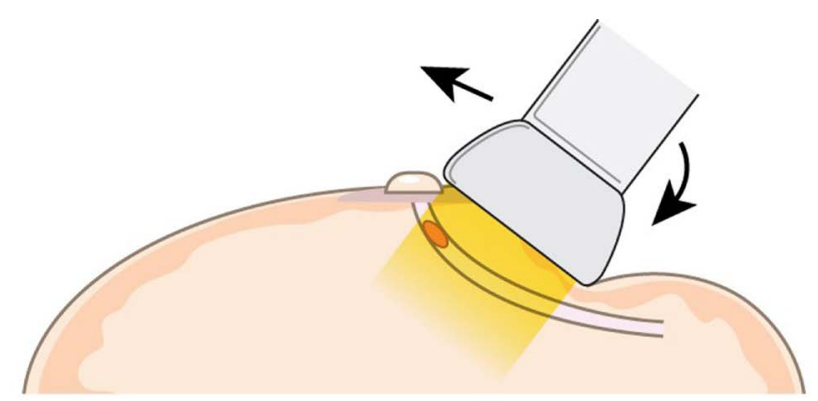

B

Fig. 6. Peripheral compression technique.

In scans of the subareolar region, the protuberance of the nipple produces acoustic shadowing that interferes with clear imaging (A). As the intraductal lesion is located, the transducer is positioned radially, parallel to the long axis of the diseased duct ( $A$, arrows). Compression is then applied first at the distal end of the transducer ( $B$, curved arrow), and then at the proximal end of the transducer, flattening out the nipple ( $B$, straight arrow). Finally, the transducer is slid towards the nipple (C, straight arrow), bending the nipple over to the other side (C, curved arrow). 
positioned in the radial axis, the performer applies compression to the nipple region with both the transducer and the free hand not used for scanning (Fig. 8). The transducer is slid distally to include the nipple, and changes in the targeted duct reveal whether the lesion is a true mass or secretory debris.

\section{Dynamic Maneuvers Using Doppler Imaging}

Another technique that can be used to distinguish between true intraductal masses and secretory material is the use of Doppler images. Dilated ductal structures filled with secretory materials easily collapse when external compression is applied, and displacement and/or changes in the echogenicity of such materials can be seen on real-time US imaging, whereas the location and US characteristics

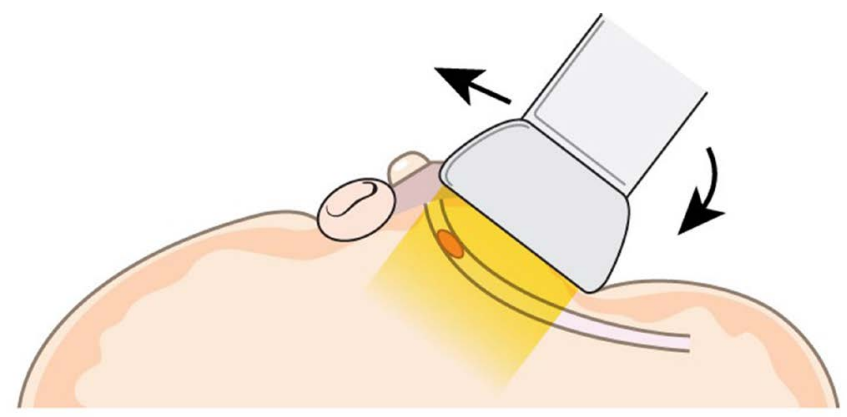

Fig. 7. Rolled-nipple technique. With the transducer positioned parallel to the long axis of the duct under investigation, the index finger of the free hand of the performer is positioned at the opposite side of the nipple. By sliding the transducer towards the nipple (straight arrow), the nipple is gradually rolled over the index finger, producing firm adherence of the probe to the skin (curved arrow) and flattening out the area that needs visualization.

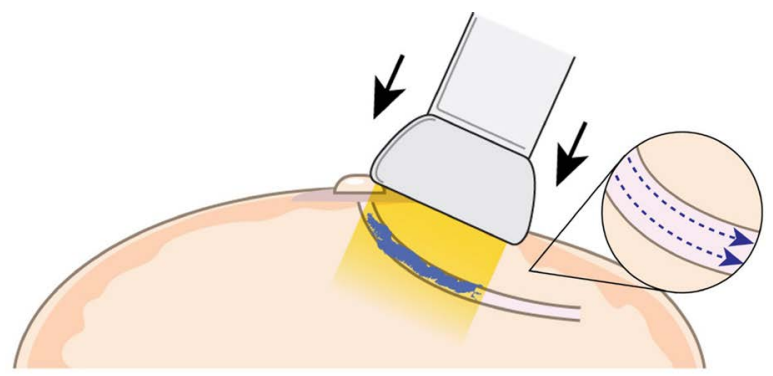

A

Fig. 9. Dynamic maneuvers using Doppler imaging.

As alternating compression ( $A$, arrows) and release ( $B$, arrows) is applied with the ultrasonography probe, the swishing movements of the intraductal contents moving back and forth generate Doppler signals, confirming the presence of secretory material rather than true intraductal masses. 


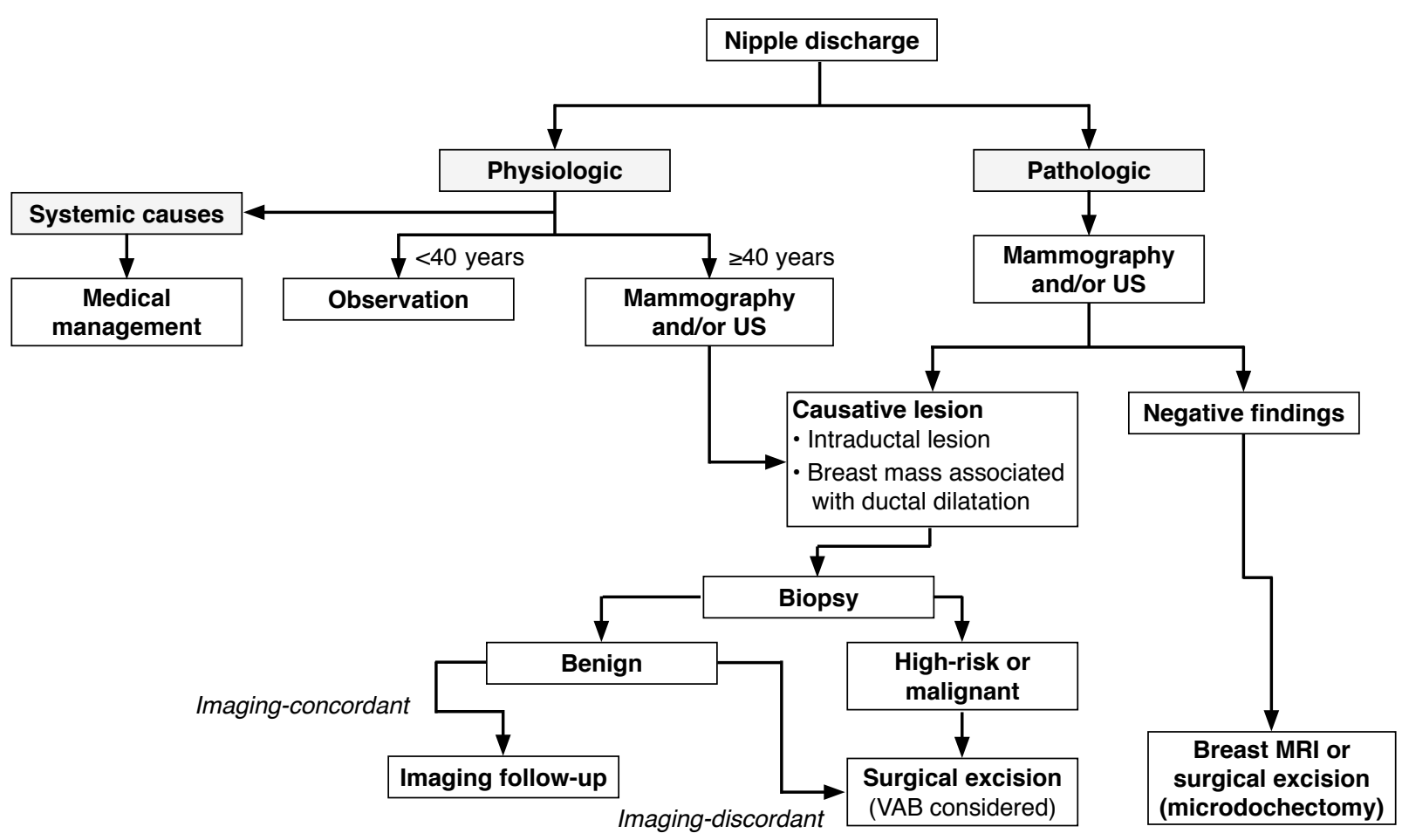

Fig. 10. Diagram showing the workflow for managing women with nipple discharge. US, ultrasonography; VAB, vacuum-assisted biopsy; $\mathrm{MRI}$, magnetic resonance imaging.

Among the methods of evaluating patients with pathologic nipple discharge, breast US has the major advantage of enabling imagingguided percutaneous biopsy, which is less invasive than surgical excision and facilitates making a preoperative diagnosis that substantially affects decision-making about management. Duct excision is an invasive procedure that can be difficult in patients in whom the affected duct cannot be localized or if the affected duct is located posteriorly, and has the risk of postoperative complications [12]. Since most patients with pathologic nipple discharge ultimately have benign conditions, a less invasive diagnostic procedure is more favorable for both the patient and clinician. Based on the pathologic diagnosis on US-guided percutaneous biopsy, conservative followup or subsequent vacuum-assisted excision can be considered for patients diagnosed with a benign lesion, while direct curative surgery can be planned for patients with a malignancy, avoiding additional surgery for diagnostic purposes.

As the accurate preoperative differential diagnosis of women with pathologic nipple discharge is difficult, diagnostic strategies combining clinical, radiological, and cytopathologic information have been proposed for diagnostic purposes and for planning the further management of patients with pathologic nipple discharge (Fig. 10) $[6,16,20]$. Among the causes of pathologic nipple discharge, intraductal papillomas, mostly in solitary form, are known to be the most common cause of pathologic nipple discharge [21]. Intraductal papilloma is part of a spectrum of papillary neoplasms ranging from benign papillomas to papillary carcinoma [22]. Distinguishing malignant papillary neoplasms from benign lesions is very difficult, even with additional immunohistochemistry staining of a biopsy specimen [23], and the significance of papillary neoplasm as a risk for breast cancer and the proper management of such neoplasms are still under debate. The rate at which papillomas are upgraded to malignancies after surgical excision has been reported to be $5 \%$ $21 \%$ [24-28], and although various factors such as older age, size, and the presence of suspicious US features have been reported to predict such an upgrade, no solid evidence exists regarding which factors can be used to predict the diagnosis of benign papillomas. Based on these upgrade rates, most studies support complete surgical excision after diagnosis [24-28]. Still, more than $80 \%$ of these masses will be confirmed as benign; therefore, more and more studies have reported the use of less invasive excision strategies, such as US-guided vacuum-assisted excision, for benign papillomas [22,29-33].

In the evaluation of patients with pathologic nipple discharge, it is not rare to encounter patients with no specific findings on any sort of examination. Based on the low risk of underlying malignancy $(0 \%-5 \%)$, several recent studies have proposed conservative follow- 
up for patients with a physical examination suggesting a benign condition, negative mammography results, and negative features on breast US $[3,10,16,32]$. Close observation and regular checkup with mammography and US for these patients are warranted; approximately $80 \%$ of cases of pathologic nipple discharge resolve spontaneously within 2 years in patients with a benign etiology [6]. If pathologic nipple discharge is persistent or recurrent after 2 years of monitoring or if the patient is unable to follow the monitoring schedule, duct exploration or excision must be considered to detect a malignancy that is occult on mammography or US $[3,12,31,32]$. In addition, using additional imaging modalities such as breast MRI, with its high sensitivity in detecting occult malignancies $[12,14,34]$, or US elastography [35] has been proposed since they may enable localization and/or provide further information regarding the causative lesion. However, at present, no strict guidelines exist regarding the evaluation or management of patients with pathologic nipple discharge, and large prospective studies are warranted to develop reasonable guidelines for these patients.

\section{Summary}

Nipple discharge results from a range of causes, which may be either physiologic or pathologic. Combining the clinical, radiological, and cytopathologic features of the patient may be useful for predicting malignancy in these patients. Breast US enables the visualization of the ductal structure and intraductal causes of pathologic nipple discharge, and facilitates a subsequent imagingguided percutaneous biopsy. Being familiar with the various US techniques that assist in the detailed visualization of subareolar ductal structures is helpful for accurately detecting and diagnosing lesions. Further prospective studies are warranted to establish standard guidelines for the management of patients with pathologic nipple discharge.

ORCID: Jung Hyun Yoon: http://orcid.org/0000-0002-2100-3513; Haesung Yoon: http://orcid.org/0000-0003-0581-8656; Eun-Kyung Kim: http://orcid.org/00000002-3368-5013; Hee Jung Moon: http://orcid.org/0000-0002-5643-5885; Youngjean Vivian Park: http://orcid.org/0000-0002-5135-4058; Min Jung Kim: http://orcid.org/0000-0003-4949-1237

\section{Conflict of Interest}

No potential conflict of interest relevant to this article was reported.

\section{Acknowledgments}

The authors would like to express their gratitude to Dong-Su Jang, MA, medical illustrator, for his help with the figures.

\section{References}

1. Patel BK, Falcon S, Drukteinis J. Management of nipple discharge and the associated imaging findings. Am J Med 2015;128:353360.

2. Sakorafas GH. Nipple discharge: current diagnostic and therapeutic approaches. Cancer Treat Rev 2001;27:275-282.

3. Morrogh M, Park A, Elkin EB, King TA. Lessons learned from 416 cases of nipple discharge of the breast. Am I Surg 2010;200:73-80.

4. Yoon H, Yoon JH, Kim EK, Moon HJ, Park BW, Kim MJ. Adding ultrasound to the evaluation of patients with pathologic nipple discharge to diagnose additional breast cancers: preliminary data. Ultrasound Med Biol 2015;41:2099-2107.

5. Cabioglu N, Hunt KK, Singletary SE, Stephens TW, Marcy S, Meric F, et al. Surgical decision making and factors determining a diagnosis of breast carcinoma in women presenting with nipple discharge. $J$ Am Coll Surg 2003;196:354-364.

6. Ashfaq A, Senior D, Pockaj BA, Wasif N, Pizzitola VJ, Giurescu ME, et al. Validation study of a modern treatment algorithm for nipple discharge. Am J Surg 2014;208:222-227.

7. Bahl M, Baker JA, Greenup RA, Ghate SV. Diagnostic value of ultrasound in female patients with nipple discharge. AJR Am J Roentgenol 2015;205:203-208.

8. Blum KS, Rubbert C, Antoch G, Mohrmann S, Obenauer S. Diagnostic accuracy of abnormal galactographic and sonographic findings in the diagnosis of intraductal pathology in patients with abnormal nipple discharge. Clin Imaging 2015;39:587-591.

9. Ferris-James DM, luanow E, Mehta TS, Shaheen RM, Slanetz PJ. Imaging approaches to diagnosis and management of common ductal abnormalities. Radiographics 2012;32:1009-1030.

10. Lippa N, Hurtevent-Labrot G, Ferron S, Boisserie-Lacroix M. Nipple discharge: the role of imaging. Diagn Interv Imaging 2015:96:1017-1032.

11. Morrogh M, Morris EA, Liberman L, Borgen PI, King TA. The predictive value of ductography and magnetic resonance imaging in the management of nipple discharge. Ann Surg Oncol 2007; 14:3369-3377.

12. Bahl M, Baker JA, Greenup RA, Ghate SV. Evaluation of pathologic nipple discharge: what is the added diagnostic value of MRI? Ann Surg Oncol 2015;22 Suppl 3:S435-S441.

13. Adepoju LJ, Chun J, El-Tamer M, Ditkoff BA, Schnabel F, Joseph $K A$. The value of clinical characteristics and breast-imaging studies in predicting a histopathologic diagnosis of cancer or high-risk lesion in patients with spontaneous nipple discharge. Am J Surg 2005;190:644-646.

14. Lorenzon M, Zuiani C, Linda A, Londero V, Girometti R, Bazzocchi $M$. Magnetic resonance imaging in patients with nipple discharge: should we recommend it? Eur Radiol 2011;21:899-907.

15. Park CJ, Kim EK, Moon HJ, Yoon JH, Kim MJ. Reliability of breast 
ultrasound BI-RADS final assessment in mammographically negative patients with nipple discharge and radiologic predictors of malignancy. J Breast Cancer 2016;19:308-315.

16. Gray RJ, Pockaj BA, Karstaedt PJ. Navigating murky waters: a modern treatment algorithm for nipple discharge. Am J Surg 2007;194:850-854.

17. D'Orsi CJ, Sickles EA, Mendelson EB, Morris EA. ACR BI-RADS Atlas: Breast Imaging Reporting and Data System. 5th ed. Reston, VA: American College of Radiology, 2013.

18. Kim WH, Chang JM, Moon WK, Cho N, Yi A, Koo HR, et al. Intraductal mass on breast ultrasound: final outcomes and predictors of malignancy. AJR Am J Roentgenol 2013;200:932-937.

19. Berg WA. Rationale for a trial of screening breast ultrasound: American College of Radiology Imaging Network (ACRIN) 6666. AJR Am J Roentgenol 2003;180:1225-1228.

20. Dolan RT, Butler JS, Kell MR, Gorey TF, Stokes MA. Nipple discharge and the efficacy of duct cytology in evaluating breast cancer risk. Surgeon 2010;8:252-258.

21. Ballesio L, Maggi C, Savelli S, Angeletti M, Rabuffi P, Manganaro $L$, et al. Adjunctive diagnostic value of ultrasonography evaluation in patients with suspected ductal breast disease. Radiol Med 2007;112:354-365.

22. Kim MJ, Kim EK, Kwak JY, Son EJ, Park BW, Kim SI, et al. Nonmalignant papillary lesions of the breast at US-guided directional vacuum-assisted removal: a preliminary report. Eur Radiol 2008; 18:1774-1783.

23. Koo JS, Han K, Kim MJ, Moon HJ, Kim EK, Park BW. Can additional immunohistochemistry staining replace the surgical excision for the diagnosis of papillary breast lesions classified as benign on 14gage core needle biopsy? Breast Cancer Res Treat 2013;137:797806.

24. Holley SO, Appleton CM, Farria DM, Reichert VC, Warrick J, Allred $D C$, et al. Pathologic outcomes of nonmalignant papillary breast lesions diagnosed at imaging-guided core needle biopsy. Radiology 2012;265:379-384.

25. Youk JH, Kim EK, Kwak JY, Son EJ, Park BW, Kim SI. Benign papilloma without atypia diagnosed at US-guided 14-gauge core- needle biopsy: clinical and US features predictive of upgrade to malignancy. Radiology 2011;258:81-88.

26. Shin HJ, Kim HH, Kim SM, Yang HR, Sohn JH, Kwon GY, et al. Papillary lesions of the breast diagnosed at percutaneous sonographically guided biopsy: comparison of sonographic features and biopsy methods. AJR Am J Roentgenol 2008;190:630-636.

27. Chang JM, Han W, Moon WK, Cho N, Noh DY, Park IA, et al. Papillary lesions initially diagnosed at ultrasound-guided vacuumassisted breast biopsy: rate of malignancy based on subsequent surgical excision. Ann Surg Oncol 2011;18:2506-2514.

28. Mercado CL, Hamele-Bena D, Oken SM, Singer Cl, Cangiarella J. Papillary lesions of the breast at percutaneous core-needle biopsy. Radiology 2006;238:801-808.

29. Hawley JR, Lawther H, Erdal BS, Yildiz VO, Carkaci S. Outcomes of benign breast papillomas diagnosed at image-guided vacuumassisted core needle biopsy. Clin Imaging 2015;39:576-581.

30. Moon SM, Jung HK, Ko KH, Kim Y, Lee KS. Management of clinically and mammographically occult benign papillary lesions diagnosed at ultrasound-guided 14-gauge breast core needle biopsy. J Ultrasound Med 2016;35:2325-2332.

31. Mosier AD, Keylock J, Smith DV. Benign papillomas diagnosed on large-gauge vacuum-assisted core needle biopsy which span $<1.5$ $\mathrm{cm}$ do not need surgical excision. Breast J 2013;19:611-617.

32. Kibil W, Hodorowicz-Zaniewska D, Popiela TJ, Kulig J. Vacuumassisted core biopsy in diagnosis and treatment of intraductal papillomas. Clin Breast Cancer 2013;13:129-132.

33. Youk JH, Kim MJ, Son EJ, Kwak JY, Kim EK. US-guided vacuumassisted percutaneous excision for management of benign papilloma without atypia diagnosed at US-guided 14-gauge core needle biopsy. Ann Surg Oncol 2012;19:922-928.

34. Sanders LM, Daigle M. The rightful role of MRI after negative conventional imaging in the management of bloody nipple discharge. Breast J 2016;22:209-212.

35. Guo X, Liu Y, Li W. Diagnostic accuracy of shear wave elastography for prediction of breast malignancy in patients with pathological nipple discharge. BMJ Open 2016;6:e008848. 